\title{
Efeitos da temperatura e da umidade dos grãos de milho nos parâmetros de qualidade tecnológica
}

\begin{tabular}{lr}
\hline Lanes Beatriz Acosta Jaques & $\begin{array}{l}\text { Instituto Federal de Educação, Ciência e Tecnologia Farroupilha. Rua Esmeralda, } \\
\text { Anderson Ely }\end{array}$ \\
$\begin{array}{lr}430 \text { - Faixa Nova - Camobi - CEP 97110-767 - Santa Maria - Rio Grande do Sul. } \\
\text { Elton Pilar Medeiros }\end{array}$ & $\begin{array}{r}\text { E-mail: lanis.acosta@hotmail.com } \\
\text { ander-ely@hotmail.com } \\
\text { Ricardo Tadeu Paraginski }\end{array}$ \\
$\begin{array}{l}\text { luana.haeberlin@gmail.com } \\
\text { elton.medeiros@iffarroupilha.edu.br } \\
\text { paraginskiricardo@yahoo.com.br }\end{array}$
\end{tabular}

Recebido em: 12 janeiro 2018. Aceito em: 6 março 2018.

DOI: http://dx.doi.org/10.21674/2448-0479.43.409-420

\section{Resumo}

Os grãos de milho são utilizados com diversas finalidades no setor agroindustrial, principalmente com destaque para uso na indústria alimentícia, necessitando de armazenamento adequado para atender a demanda de matéria-prima com qualidade ao longo do ano. Dentre os fatores que interferem na qualidade de armazenamento, a temperatura, umidade dos grãos e o tempo de armazenamento são os principais. Desta forma, o objetivo no trabalho foi avaliar a qualidade de grãos de milho armazenados com teores de umidade de 12, 15 e 18\% nas temperaturas de 15, 25 e $35 \stackrel{\circ}{ } \mathrm{C}$, durante 180 dias de armazenamento. Os parâmetros umidade, classificação comercial, teor de grãos mofados, condutividade elétrica e teor de germinação foram avaliados no início e a cada 45 dias. Os resultados indicaram que nas umidades de $15 \%$ e $18 \%$, na temperatura de $35{ }^{\circ} \mathrm{C}$, ocorrem maiores reduções nos parâmetros de avaliação de qualidade, sendo que na temperatura de $15^{\circ} \mathrm{C}$ e umidade de $12 \%$ a melhor conservação dos grãos nos três teores de água ao longo do período de 180 dias.

Palavras-chave: Ambiente. Armazenamento. Milho. Tecnologia. Ambiente.

\section{Abstract}

\section{Effects of temperature and moisture of maize on the parameters of technological quality}

Maize kernels are used for various purposes, especially for use in the food industry, and therefore require adequate storage to meet the demand for quality raw material throughout the year, and grain temperature and humidity are the main Factors that interfere with this quality. The objective of this study was to evaluate the quality of stored corn grains with moisture contents of 12,15 and $18 \%$ at temperatures of 15,25 and $35 \stackrel{\circ}{\circ} \mathrm{C}$ during 180 days of storage. The parameters moisture, commercial classification, moldy grain content, electrical conductivity and germination content were evaluated at 
the beginning and every 45 days. The results indicated that in the $15 \%$ and $18 \%$ moisture content, at $35{ }^{\circ} \mathrm{C}$, there are larger reductions in the quality evaluation parameters. In the temperature of $15{ }^{\circ} \mathrm{C}$ occurs the best conservation of the grains in the three water contents in the period of 180 days.

Keywords: Environment. Storage. Maize. Technology. Environment.

\section{Introdução}

A produção brasileira de grãos de milho (Zea mays L.) na safra de 2015/2016 foi aproximadamente 86 milhões de toneladas (CONAB, 2016), sendo este total de produção utilizado em diferentes setores, como alimentação animal, e na humana na forma industrializada ou consumo in natura, necessitando os grãos possuírem qualidade elevada para atender a necessidade dos consumidores. Os grãos de milho são produzidos em duas safras, e necessitam de armazenamento durante o restante do período do ano para atender a demanda, entretanto muitas vezes por déficit de armazenamento, ou mesmo por falta de informações, os grãos acabam sendo armazenados de forma incorreta, em condições inadequadas que acabam comprometendo a qualidade do produto.

Dentre os vários fatores que interferem na qualidade de armazenamento dos grãos, a temperatura é um dos principais (REHMAN et al., 2002; REED et al., 2007; PARK et al., 2012; PARAGINSKI et al., 2014), e desta forma, a cada ano aumenta a utilização de tecnologias para redução desta no interior da massa de grãos durante o armazenamento, buscando preservar a qualidade dos grãos por maiores períodos com segurança, evitando que ocorra uma redução da qualidade dos grãos. A técnica de resfriamento consiste em reduzir a temperatura no interior dos armazéns e silos verticais, caracterizados como sistemas semi-herméticos de armazenamento, onde ocorre insuflação de ar frio e seco para o interior do silo até a obtenção das temperaturas desejadas pelo produtor.

Os grãos de milho armazenamento energia na forma de lipídios, proteínas e carboidratos, sendo que essas reservas armazenadas no tecido de sustentação são desdobradas, transportadas e ressintetizadas no eixo embrionário através de reações bioquímicas, enzimáticas e metabólicas dos grãos, e conforme trabalhos realizados por Perez-Garcia e Gonzalez-Benito (2006) e Aguiar et al. (2012), a redução da temperatura, diminui a velocidade dessas reações, e consequentemente mantém a qualidade dos grãos por períodos mais longos. Trabalhos com uso de resfriamento artificial já foram realizados em grãos (Rigueira et al., 2009; Oliveira et al., 2011; Park et al., 2012), porém, poucos trabalhos foram realizados com grãos de milho. Demito e Afonso (2009) destacam em seu estudo que a redução da temperatura a níveis de refrigeração pode ser uma tecnologia promissora na manutenção da qualidade dos grãos, retardando o desenvolvimento de insetos, praga e da microflora presente, independente das condições climáticas da região. Rigueira et al. (2009) salientaram que armazenar a produção em sistemas onde se reduz a temperatura é uma técnica eficaz e economia por longos períodos. 
Desta forma, informações a respeito do comportamento dos grãos frente a diversas condições de temperatura e umidade podem auxiliar na tomada de decisão sobre armazenamento seguro por períodos mais prolongados, e reduzir as perdas qualitativas dos grãos. Assim, o objetivo no trabalho foi avaliar a qualidade físico-química de grãos de milho com 12, 15 e 18\% de umidade, armazenados por 180 dias nas temperaturas de 15,25 e $35^{\circ} \mathrm{C}$, determinando condições seguras de armazenamento, identificando temperaturas e umidades que não sejam fatores de riscos para grãos de milho.

\section{Material e Métodos}

O trabalho foi desenvolvido no Laboratório de Classificação de Grãos do Instituto Federal de Educação, Ciência e Tecnologia Farroupilha - Campus Alegrete, Rio Grande do Sul, Brasil. Utilizaram-se grãos de milho (Zea mays L.), grupo semi-duro, classe amarela, variedade comercial, produzidos no município de São Francisco de Assis - RS, Brasil, latitude S 29³3'56”, longitude O $54^{\circ}$ 54'3" e altitude de 155 metros na safra 2014/2015. As espigas foram colhidos manualmente, com umidade de $27 \%$, sendo a trilha e limpeza das amostras realizada manualmente. Após a limpeza, os grãos foram submetidos a secagem artificial em estufa com temperatura de ar de $40{ }^{\circ} \mathrm{C}$ até a obtenção das umidades de 12, 15 e 18\%. Os grãos foram armazenados em sacos de polietileno de $0,2 \mathrm{~mm}$ de espessura de filme plástico, com dimensões de $30 \times 30 \times 30 \mathrm{~cm}$, com capacidade de $1 \mathrm{Kg}$, vedados em máquina Webomatic, e posteriormente dispostos em pilhas nas temperaturas de 15, $25 \mathrm{e}$ $35^{\circ} \mathrm{C}$ em estufa incubadora para B.O.D com desumidificação, marca Eletrolab, Linha EL 141, onde permaneceram durante 180 dias. As avaliações foram realizadas no dia zero, aos 45, 90, 135 e 180 dias. Foi utilizado o delineamento inteiramente casualizado em esquema fatorial $(3 \times 3 \times 5)$, com 3 umidades, 3 temperatura e 5 tempos armazenamento, com três repetições para cada temperatura em cada tempo de coleta. Realizou-se análise de variância ANOVA, a 5\% de probabilidade para as variáveis utilizando software SAS INSTITUTE (2002).

\section{Classificação dos grãos}

A classificação dos grãos foi realizada por classificador oficial de grãos registrado no MAPA Ministério da Agricultura Pecuária e Abastecimento com número EAC 1.867, de acordo com a Instrução Normativa MAPA n 60, de 22 de dezembro de 2011, publicada no D.O.U de 23.11.2011. Os defeitos identificados e pesados para tipificação foram ardidos, chochos, imaturos, fermentados, germinados, gessados e mofados.

\section{Teor de água}

Para determinação do teor de água, foi utilizado o método de estufa com circulação de ar, à temperatura de $105 \pm 1^{\circ} \mathrm{C}$, durante 24 horas, em três repetições, de acordo com recomendações da American Society of Agricultural Engineers (ASAE, 2000). 


\section{Teor de grãos mofados}

O teor de grãos mofados foi determinado em triplicata de 100 gramas de grãos, de acordo com metodologia da ISTA (2004), com adaptações. Foram considerados para quantificação do teor de mofados, grãos ou pedaços de grãos que apresentavam contaminações fúngicas (mofo ou bolor) visíveis a olho nu, independentemente do tamanho da área atingida, bem como os grãos ou pedaços de grãos que apresentavam coloração esverdeada ou azulada no germe, produzida pela presença de fungos.

\section{Condutividade elétrica}

A condutividade elétrica da água de hidratação foi determinada segundo metodologia do International Seed Testing Association - ISTA (2008). Onde foram contadas 4 repetições de 25 grãos, pesados e imersos em $75 \mathrm{~mL}$ de água deionizada (em becker de $250 \mathrm{~mL}$ ), colocadas em germinador regulado para a temperatura constante de $20^{\circ} \mathrm{C}$, e posteriormente incubados durante 24 horas. As soluções foram agitadas suavemente e a condutividade elétrica foi determinada com condutivímetro sem filtragem da solução. Os resultados foram expressos em $\mu \mathrm{S} . \mathrm{cm}^{-1}$.

\section{Germinação}

O teor de germinação foi conduzido em quatro repetições de 50 sementes por lote, em rolo de papel toalha, em germinador regulado a $25^{\circ} \mathrm{C}$, embebido em água na quantidade de 2,5 vezes o peso do substrato seco, visando adequado umedecimento, com as contagens feitas no $5^{\circ}$ dia após a semeadura, seguindo as Regras para Análise de Sementes (BRASIL, 2009). Os resultados foram expressos em percentagem pela média das repetições.

\section{Resultados e Discussão}

Os resultados de classificação dos grãos (Tabela 1) indicam que até os 180 dias de armazenamento os grãos com umidade de $12 \%$ foram classificados de acordo com a IN MAPA № 11 de 2011 como Tipo 1, em todas as temperaturas de armazenamento. Os grãos com umidade de $15 \mathrm{e}$ $18 \%$ foram classificados como Tipo 1 em todas as temperaturas até 90 dias de armazenamento, sendo que a partir dos 90 dias, houve uma redução na qualidade do produto, sendo esses classificados como abaixo do padrão comercial e Tipo 2, nas temperaturas de $35^{\circ} \mathrm{C}$. Nas três umidades os grãos armazenados foram classificados como Tipo 1 nas temperaturas de 15 e $25^{\circ} \mathrm{C}$ ao longo dos 180 dias de armazenamento.

Tabela 1. Classificação dos grãos de milho armazenados durante 180 dias em sistema semi-hermético nas diferentes condições de umidade e temperatura, de acordo com o Regulamento Técnico do MAPA (BRASIL, 2011). 


\begin{tabular}{|c|c|c|c|c|c|c|}
\hline \multicolumn{2}{|c|}{ Condições de armazenamento } & \multicolumn{5}{|c|}{ Tempo de armazenamento (dias) } \\
\hline Umidade (\%) & $\begin{array}{c}\text { Temperatura } \\
\left({ }^{\circ} \mathrm{C}\right)\end{array}$ & 0 & 45 & 90 & 135 & 180 \\
\hline \multirow{3}{*}{12} & 15 & Tipo 1 & Tipo 1 & Tipo 1 & Tipo 1 & Tipo 1 \\
\hline & 25 & Tipo 1 & Tipo 1 & Tipo 1 & Tipo 1 & Tipo 1 \\
\hline & 35 & Tipo 1 & Tipo 1 & Tipo 1 & Tipo 1 & Tipo 1 \\
\hline \multirow{3}{*}{15} & 15 & Tipo 1 & Tipo 1 & Tipo 1 & Tipo 1 & Tipo 1 \\
\hline & 25 & Tipo 1 & Tipo 1 & Tipo 1 & Tipo 1 & Tipo 1 \\
\hline & 35 & Tipo 1 & Tipo 1 & Tipo 1 & Tipo 2 & AP \\
\hline \multirow{3}{*}{18} & 15 & Tipo 1 & Tipo 1 & Tipo 1 & Tipo 1 & Tipo 1 \\
\hline & 25 & Tipo 1 & Tipo 1 & Tipo 1 & Tipo 1 & Tipo 1 \\
\hline & 35 & Tipo 1 & Tipo 1 & Tipo 1 & $\mathrm{AP}^{*}$ & $\mathrm{AP}^{*}$ \\
\hline
\end{tabular}

* AP - Abaixo do padrão de comercialização.

Os resultados dos grãos armazenados com $18 \%$ de teor de água na temperatura de $35^{\circ} \mathrm{C}$ estão de acordo com Costa et al. (2010), afirmando que grãos armazenados com esta umidade apresentam maior redução de qualidade, sendo o teor de grãos mofados o principal fator que resultou na redução da qualidade destes. Isso pode estar relacionado com a temperatura sendo um fator que afeta a armazenagem de grãos, juntamente com a umidade tornando-se um fator crucial para integração de fatores bióticos e abióticos que promovem a deterioração do grão, onde práticas inadequadas de armazenamento proporcionam condições para o desenvolvimento fungico. De acordo com Mukanga et al. (2010), os gêneros de fungos mais importantes associados com milho são Fusarium e Aspergillus, que podem produzir micotoxinas e aumentar o risco de doenças cancerígenas e degenerativas nos consumidores.

Os resultados do teor de umidade (Figura 1) indicam que o teor de umidade nos grãos armazenados com 12\% apresentou variações ao longo de 180 dias de armazenamento nas temperaturas de 15,25 e $35{ }^{\circ} \mathrm{C}$. Na umidade de $15 \%$ a $35^{\circ} \mathrm{C}$ ocorreu uma redução de $15,2 \%$ para $8,10 \%$ ao final de 180 dias de armazenamento. A umidade de $18 \%$ também apresentou redução a temperatura de $35^{\circ} \mathrm{C}$, estando de acordo com estudos realizados por Faroni et al. (2005), que observou decréscimo no teor de água dos grãos de milho, ao longo do período de armazenamento, para as temperaturas acima de $25^{\circ} \mathrm{C}$, com teor de água dos grãos variando de $13,5 \%$ base úmida, no início do experimento, a 12,5 e $10,5 \%$, para as temperaturas de 30 e $40 \stackrel{\circ}{\circ}$, respectivamente, durante 6 meses de armazenamento. As alterações observadas podem ser atribuídas principalmente ao sistema de armazenamento que foi empregado, onde temperaturas de armazenamento altas intensificam o processo respiratório dos grãos, liberando $\mathrm{CO}_{2}$ (dióxido de carbono) e consumindo $\mathrm{O}_{2}$ (oxigênio), através de trocas gasosas. A redução do teor de água dos grãos observada nos grãos armazenados na temperatura de $35{ }^{\circ} \mathrm{C}$ é resultado do equilíbrio higroscópico dos grãos com as condições do ambiente de armazenamento, sendo que quando a pressão de vapor do grão é maior que a do ar circundante, ocorre o fenômeno de dessorção havendo transferência de vapor de água para o ar reduzindo, desta forma, a umidade dos grãos (SILVA et al., 1995). 

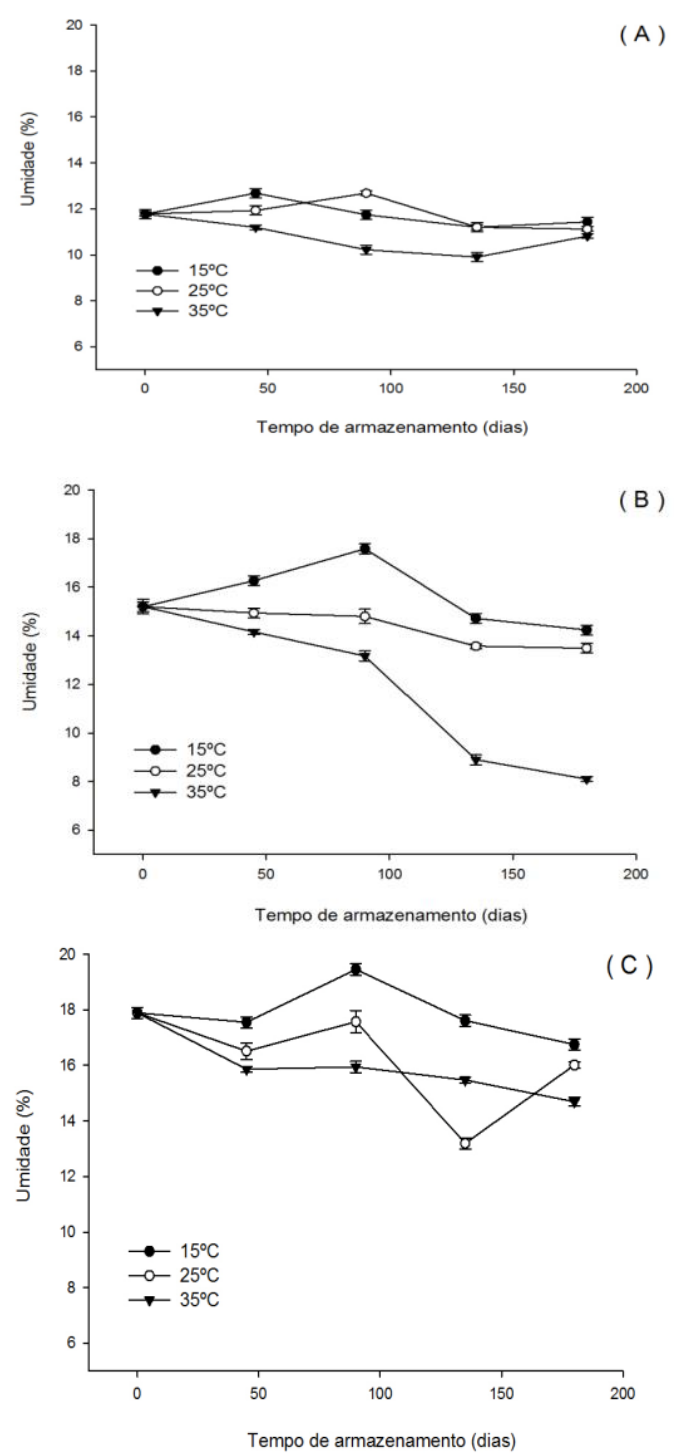

Figura 1. Teor de água (\%) dos grãos de milho armazenados com umidade de $12 \%$ (A), $15 \%$ (B) e $18 \%$ (C) nas temperaturas de 15,25 e $35^{\circ} \mathrm{C}$ durante 180 dias.

Os resultados do teor de grãos mofados dos grãos armazenados com umidade de 12, $15 \mathrm{e}$ $18 \%$ nas temperaturas de 15,25 e $35 \stackrel{\circ}{ } \mathrm{C}$ são apresentados na Figura 2.

Os resultados de grãos mofados indicam que ocorreu um aumento na ocorrência de grãos mofados nas três umidades de armazenamento estudadas. Na umidade de $12 \%$ houve aumento, mas não interferiu na tipificação, entretanto maiores valores observados foram nos grãos com umidade 15 e $18 \%$ na temperatura de $35^{\circ} \mathrm{C}$, reduzindo a qualidade final do produto e aumentando os riscos aos consumidores. Os aumentos ocorreram principalmente após 135 dias de armazenamento, onde o teor de grãos mofados chegou a $100 \%$ ao final de 180 dias para os tratamentos com umidade de $15 \%$ e temperatura de $35{ }^{\circ} \mathrm{C}$, e na umidade de $18 \%$ e temperatura de $35 \%$ após 90 dias apresentou $100 \%$ de grãos mofados, sendo esse aumento resultado da maior umidade dos grãos.

Condições de armazenamento que promovem um aumento da intensidade da respiração dos grãos são prejudiciais, porque produzem mudanças nas suas propriedades físicas e químicas que os 
tornam inúteis para o consumo "in natura" ou processamento industrial. Temperaturas e umidades baixas, fazem com que os fatores de deterioração dos grãos sejam reduzidos, pois os grãos depois de colhidos continuam a viver, e como todos os organismos vivos, eles respiram e através do processo respiratório eles estão sujeitos a transformações continuadas.

Para Frisvad et al. (2006), a redução natural do valor nutricional dos grãos de milho, juntamente com a produção de micotoxinas, são consequências do ataque de fungos. Alimentos com presença de micotoxinas são um sério problema para a saúde pública e para a qualidade dos alimentos, e cuidados devem ser tomados desde a pré-colheita até a pós-colheita dos grãos durante o beneficiamento, armazenamento e transporte. Armazenar grãos com umidades baixas pode ser uma solução para evitar o desenvolvimento fungico, sendo que o gênero Aspergillus se desenvolve com elevada umidade.
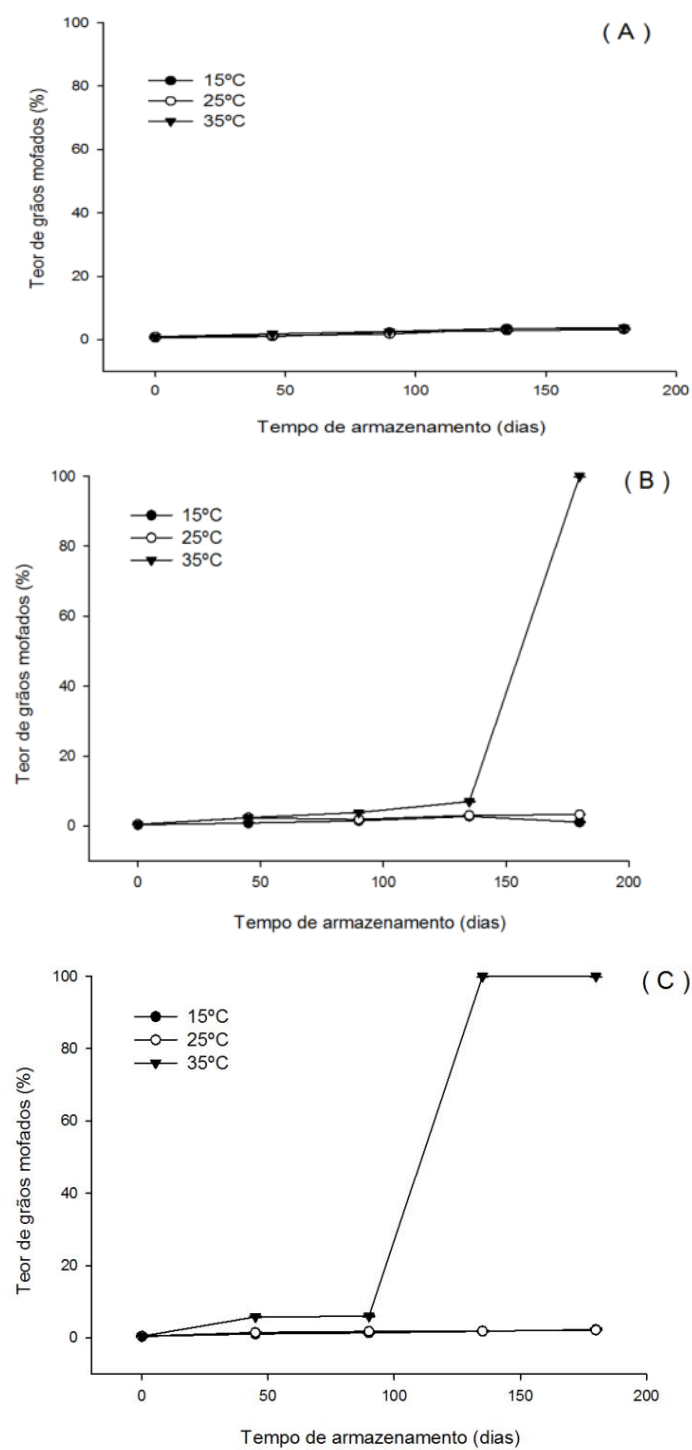

Figura 2. Teor de grãos mofados (\%) dos grãos de milho armazenados com umidade de $12 \%(\mathrm{~A})$, $15 \%$ (B) e $18 \%$ (C) nas temperaturas de 15,25 e $35 \stackrel{\circ}{\circ}$ durante 180 dias. 
Os resultados de condutividade elétrica apresentados na Figura 3 indicam um aumento da condutividade, resultado de um processo de deterioração da membrana e da parede celular mais acelerado. A condutividade elétrica quantifica a lixiviação de substâncias ionizantes, que ocorre nos grãos em função dos danos mecânicos e, ou térmicos causados na estrutura celular (CORADI et al., 2014). Observa-se na Figura 3, que a condutividade elétrica foi mais expressiva com o aumento da temperatura, e consequentemente, ocorreu redução da qualidade.

Os grãos armazenados em temperaturas de 15 e $25{ }^{\circ} \mathrm{C}$ apresentaram um valor de condutividade elétrica mais baixo, estando de acordo com estudos realizados por Smaniotto et al. (2014), que avaliaram a qualidade fisiológica de soja durante o armazenamento e descobriram que na temperatura de $20^{\circ} \mathrm{C}$, os grãos se mantiveram com melhor qualidade, em função do teste de condutividade elétrica, comparado com o grão armazenado em temperaturas mais altas, com os mesmos teores de água.

De acordo com Vieira e Krzyzanowski (1999), grãos com maiores valores de condutividade elétrica caracterizam-se por apresentarem maiores taxas de degradação da membrana celular e consequentemente menor vigor. Trabalhos de Krishnan et al. (2004), estudaram as características termodinâmicas da soja durante o armazenamento sob condições de envelhecimento acelerado, e também verificaram valores médios maiores de condutividade elétrica da solução que continha os grãos à medida que se utilizavam temperaturas mais elevadas ao longo do período de armazenamento.

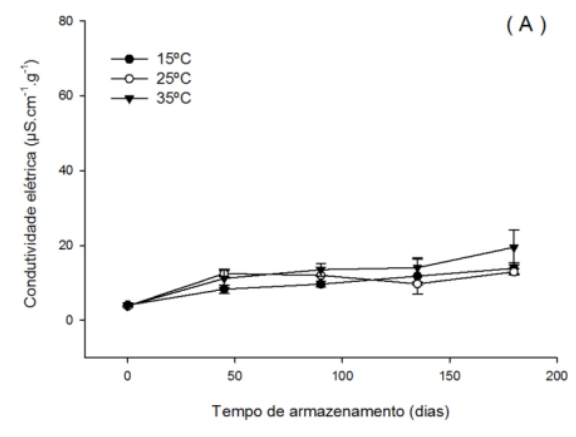



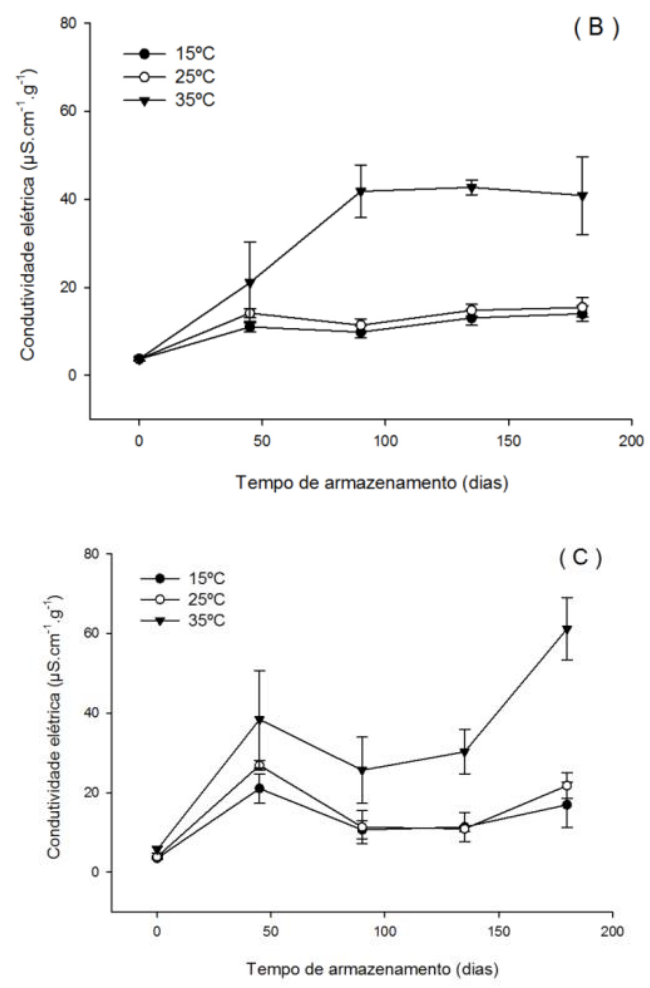

Figura 3. Condutividade elétrica $\left(\mu \mathrm{S} \cdot \mathrm{cm}^{-1} \cdot \mathrm{g}^{-1}\right)$ dos grãos de milho armazenados com umidade de $12 \%(\mathrm{~A}), 15 \%$ (B) e $18 \%$ (C) nas temperaturas de 15,25 e $35^{\circ} \mathrm{C}$ durante 180 dias.

Os resultados do teor de germinação (Figura 4) indicam que ocorreu redução do potencial de germinação, independente do teor de água e da temperatura, sendo as menores reduções verificadas nas temperaturas baixas de armazenamento, pois apresentaram melhor potencial fisiológico. Puzzi (1989) afirma que em temperaturas mais baixas, os grãos podem ser armazenados com maior segurança do que em climas mais quentes. Na temperatura de $35^{\circ} \mathrm{C}$, a redução da germinação foi mais acentuada para o teor de água de 15\% e 18\%, chegando a zero nos 135 dias de armazenamento, comparando-se com a de $12 \%$, para as mesmas condições para o tempo de armazenamento. Resultados semelhantes foram obtidos por Elencar (2006), quando armazenou soja nas temperaturas de 25,30 e $35^{\circ} \mathrm{C}$, a redução foi mais acentuada à medida que se elevou o teor de água dos grãos, chegando a zero nos 135 dias.

O efeito da temperatura e umidade relativa na viabilidade de milho foi estudado por Abba e Lovato (1999), que armazenaram sementes com $10,5 \%$ b.u. a $30^{\circ} \mathrm{C}$ e $95 \%$ de U.R., e verificaram perda da capacidade germinativa do milho após 42 dias de armazenamento. Pronyk et al. (2006) também verificou decréscimo significativo do percentual de germinação devido a interação entre temperatura, conteúdo de água e tempo de armazenagem.

Conforme trabalhos de Rodríguez et al. (2004), os grãos de milho após serem armazenados em silos bolsa com teor de água de 14,8 e 19,5\% (b.u.), obtiveram um decréscimo na germinação em ambas as condições, após 153 dias, sendo que esse decréscimo do teor de germinação dos grãos decorre das alterações que ocorrem na estrutura das membranas dos grãos, sendo que quando a temperatura e a umidade dos grãos são elevadas, as alterações são mais significativas, resultando em perda da qualidade final do produto em curtos períodos de tempo. 


\section{Conclusão}

1. Para fins de comercialização de grãos de milho, foi possível armazenar em sistema semihermético por 180 dias grãos com teor de água de $12 \%$ nas temperaturas de 15,25 e $35^{\circ} \mathrm{C}$ e grãos com teor de água de 15 e $18 \%$ nas temperaturas de 25 e $35^{\circ} \mathrm{C}$, sem alterar o tipo final referente à classificação do produto. Os grãos com teor de água de 15 e $18 \%$ na temperatura de $35{ }^{\circ} \mathrm{C}$ não apresentaram alteração no tipo final do produto por até 90 dias.

2. Os grãos de milho com umidade de $12 \%$ nas temperaturas de 15 e $25{ }^{\circ} \mathrm{C}$, mantiveram a qualidade fisiológica satisfatória por 180 dias. Os grãos armazenados com teor de água de 15 e $18 \%$ nas temperaturas de 15 e $25{ }^{\circ} \mathrm{C}$ mantiveram a qualidade por 90 dias. As temperaturas de $35^{\circ} \mathrm{C}$ apresentaram reduções bem acentuadas para a três umidades estudas, impossibilitando um armazenamento maior que 45 dias.

3. O tempo de armazenamento provoca alterações nas propriedades físicas dos grãos, sendo que as maiores alterações nos parâmetros avaliados ocorrem nas maiores umidades de grãos e nas maiores temperaturas de armazenamento. Armazenar com umidade de $18 \%$ provoca reduções nos parâmetros de germinação, tipificação e aumento na condutividade elétrica e teor de grãos mofados em temperaturas de 25 e $35^{\circ} \mathrm{C}$.

4. A utilização de temperaturas baixas possibilita o armazenamento dos grãos de milho com umidades superiores a $12 \%$ por períodos prolongados

\section{Agradecimentos}

Gostaríamos de agradecer ao CNPq (Conselho Nacional de Desenvolvimento Científico e Tecnológico), SCT-RS (Secretaria da Ciência, Inovação e Desenvolvimento Técnológico do Estado do Rio Grande do Sul), a Fapergs (Fundação de Amparo à Pesquisa do Estado do Rio Grande do Sul) e ao Instituto Federal Farroupulha - Campus Alegrete.

\section{Referências}

ABBA, E.J.; LOVATO, A. Effect of seed storage temperature and relative humidity on maize (Zea mays L.) seed viability and vigour. Seed Science and Technology, Zurich, v. 27, p. 101-114, 1999.

AGUIAR, R.W.S. et al. Efeito do dióxido do carbono, temperatura e armazenamento sobre sementes de soja e micoflora associada. Revista Ciência Agronômica, v.43, n.3, p.554-560, 2012.

AMERICAN SOCIETY OF AGRICULTURAL ENGINEERS - ASAE. Moisture measurement Unground grain and seeds. [S.L.]: ASAE, 2000. 
BRASIL. Mistério da Agricultura, Pecuária e Abastecimento. Instrução Normativa $n^{\circ} 60$, de 22 de dezembro de 2011. Regulamento Técnico do Milho. Diário Oficial da União. 23.12.2011, Brasília, DF.

BRASIL. Ministério da Agricultura, Pecuária e Abastecimento. Regras para análise de sementes / Ministério da Agricultura, Pecuária e Abastecimento. Secretaria de Defesa Agropecuária. - Brasília: Mapa/ACS, 2009.

CORADI, P.C.; BORÈM, F.M.; REINATO, C.H. Coffee cherries drying process and the influence of environment relative humidity in the mathematical modeling, moisture content, and enthalpy of vaporization. Energia na Agricultura, 2014.

COSTA, A.R. et al. Qualidade de grãos de milho armazenados em silos bolsa. Revista Ciência Agronômica, v.41, n.2, p.200-207, 2010.

DEMITO, A.; AFONSO, A.D.L. Qualidade das sementes de soja resfriadas artificialmente. Engenharia na Agricultura, v.17, p.7-14, 2009.

ELENCAR, R. E. Efeitos das condições de armazenagem sobre a qualidade de soja e do óleo bruto. Dissertação (Mestrado) - Universidade Federal de Viçosa. Viçosa, Minas Gerais, 2006.

FARONI, L.R.A. et al. Avaliação qualitativa e quantitativa do milho em diferentes condições de armazenamento. Engenharia na Agricultura, v.13, n.3, p.193-201, 2005.

FRISVAD, J.C. et al. Important mycotoxins and the fungi which produce them. Advances in Experimental Medicine and Biology, v.571, p.3-31, 2006.

INTERNATIONAL SEED TESTING ASSOCIATION - ISTA. Determination of other seeds by number. Cap.4. In:_ International rules for seed testing. Bassersdorf, 2008.

INTERNATIONAL SEED TESTING ASSOCIATION - ISTA. International Rules for Testing Seeds. Seed Science and Technology, Zurich, v. 32, 2004.

KRISHNAN, P.; NAGARAJAN, S.; MOHARIR, A.V. Thermodynamic characterization of seed deterioration during storage under accelerated ageing conditions. Biosystems Engineering, London, v. 89 , n. 4 , p. 425-433, 2004.

MUKANGA, M. et al. Survey of pre-harvest ear rot diseases of maize and associated mycotoxins in south and central Zambia. Journal Food Microbiology, v. 141, p. 213-221, 2010.

OLIVEIRA, V.R. et al. Qualidade para o cozimento e composição nutricional de genótipos de feijão com e sem armazenamento sob refrigeração. Ciência Rural, v.41, n.5, p.746-752, 2011.

PARAGINSKI, R.T. et al. Physicochemical and pasting properties of maize as affected by storage temperature. Journal of Stored Products Research, v.49, p.209-214, 2014.

PARK, C. E. et al. Changes in physicochemical characteristics of rice during storage at different temperatures. Journal of Stored Products Research, v.48, p.25-29, 2012.

PEREZ-GARCIA, F.; GONZALEZ-BENITO, M.E. Seed germination of five Helianthemum species: Effect of temperature and presowing treatments. Journal of Arid Environments, v.65, n.1, p.688693, 2006.

PRONYK, C. et al. Correlation of total ergosterol levels in stored canola with fungal deterioration. Journal of Stored Products Research, Oxford, v. 42, p. 162-172, 2006.

PUZZI, D. Abastecimento e armazenagem de grãos. Campinas: Instituto Campineiro de Ensino Agrícola, 1989. 
REED, C. et al. Response of storage molds to different initial moisture contents of maize (corn) stored at $25^{\circ} \mathrm{C}$, and effect on respiration rate and nutrient composition. Journal of Stored Products Research, v.43, n.4, p.443-458, 2007.

REHMAN, Z-U.; HABIB, F.; ZAFAR, S. I. Nutritional changes in maize (Zea mays) during storage at three temperatures. Food Chemistry, v.77, n.2, p.197-201, 2002.

RIGUEIRA, R.J.A.; LACERDA FILHO, A.F.; VOLK, M.B.S. Avaliação da qualidade do feijão armazenado em ambiente refrigerado. Alimentos e Nutrição, v.20, n.4, p.649-655, 2009.

RODRíGUEZ, J. C. et al. IP short term storage of Argentine cereals in silobags to prevent spoilage and insects. In: I INTERNATIONAL QUALITY GRAINS CONFERENCE, 2004, Indianapolis, Proceeding. Indianapolis: US Quality Grains Research Consortium, p. 1-15, 2004.

SILVA, J.S.; AFONSO, A.D.L.; LACERDA FILHO, A.F. Secagem e armazenagem de produtos agrícolas. In: Silva, J. S. Pré-processamento de produtos agrícolas. Juiz de Fora: Instituto Maria, 1995, p.395-462.

SMANIOTTO, T.A.S. et al. Qualidade fisiológica das sementes de soja armazenadas em diferentes condições. Revista Brasileira de Engenharia Agrícola e Ambiental, Campina Grande, v. 18, n.4, p. 446-453, 2014.

VIEIRA, R.D.; KRZYZANOWSKI, F.C. Teste de condutividade elétrica. In: KRZYZANOWSKI, F.C.; VIEIRA, R.D.; FRANÇA NETO, J.B. (Eds). Vigor de sementes: conceitos e testes. Londrina: ABRATES, 1999. cap.4. 